\title{
Use of Laser Technologies in the Treatment and Rehabilitation of Ischemic Stroke in Gerontological Patients
}

ISSN: 2578-0093

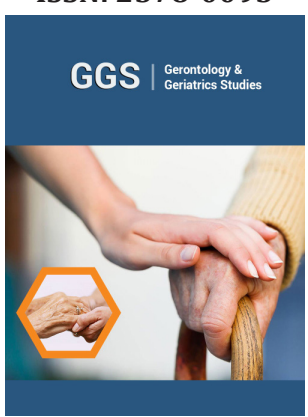

*Corresponding author: Maksimovich IV, Clinic of Cardiovascular Diseases named after Most Holy John Tobolsky, Russia

Submission: 悳 November 15, 2019

Published: November 18, 2019

Volume 5 - Issue 3

How to cite this article: Maksimovich IV. Use of Laser Technologies in the Treatment and Rehabilitation of Ischemic Stroke in Gerontological Patients. Gerontol \& Geriatric stud.5(3). GGS.000612.2019. DOI: $10.31031 /$ GGS.2019.05.000612

Copyright@ Maksimovich IV, This article is distributed under the terms of the Creative Commons Attribution 4.0 International License, which permits unrestricted use and redistribution provided that the original author and source are credited.

\section{Maksimovich IV*}

Clinic of Cardiovascular Diseases named after Most Holy John Tobolsky, Russia

\section{Abstract}

Keywords: PBMT; Photo biomodulation therapy; Intracerebral transcatheter laser PBMT; Percutaneous transluminal laser angioplasty (PTLA)

\section{Editorial}

The brain is the most vascularized organ - it contains from 3 to 4 thousand capillaries in one cubic centimeter of cerebral tissue, which is significantly higher than that of any other human organs and tissues. This need of cerebral tissue for high capillary blood flow leads to the fact that the slightest disturbances in blood supply cause impaired tissue metabolism, development of hypoxia, death of mitochondria in neurons, ischemia and stroke [1]. The number of ischemic strokes is constantly increasing all over the world leading to high mortality and disability of the population. This requires development of new, highly effective methods of treating and rehabilitating stroke patients. The treatment of ischemic stroke should be pathogenetically substantiated, comprehensive, aimed at improving and restoring blood supply, restoring metabolic processes, synthesizing adenosine triphosphate (ATP) in the mitochondria of neurons, and regenerating cerebral tissues.

One of the most promising areas in the treatment of ischemic cerebral strokes is the use of laser technologies, which currently has two directions:

a) laser with low output power, by means of which various types of Photo biomodulation Therapy (PBMT) are carried out. Depending on the localization of exposure, PBMT is subdivided into transcranial PBMT [2-5], Intranasal PBMT [3-5], and transcatheter endocerebral PBMT [6].

b) laser with high output power, which is used to conduct Percutaneous Transluminal Laser Angioplasty (PTLA) [7,8]

For PBMT, laser systems operating in the red and near-infrared (NIR) range of the light spectrum $(600-1100 \mathrm{~nm})$ are used. When carrying out any PBMT methods, the use of these light energy sources does not cause damage to brain tissue [2-6]. In the red and NIR spectral ranges, cerebral tissues do not absorb much laser energy. Low absorption leads to a sufficiently large depth of penetration of laser energy, which is extremely important when conducting PBMT, as it allows to affect not only the irradiated surface, but also more deeply located tissues. With a direct effect on the brain, the depth of light penetration in the red range is from 20 to $40 \mathrm{~mm}$, in the near-infrared range it is over $50 \mathrm{~mm}$ [4-6]. The mechanism of therapeutic effect when using laser with low output power of the red and near-infrared spectral regions is complex. It means stimulating angiogenesis, which causes collateral and capillary revascularization of ischemic cerebral tissues, improving cerebral tissue oxygenation, stimulating and restoring ATP metabolism in neuron mitochondria, restoring tissue metabolism, restoring synaptic connections, stimulating neurogenesis and regenerating damaged tissue [2-6]. The transcranial PBMT method implies the effect of laser energy on the brain through the scalp and skull using special light-guiding devices and helmets for this purpose, which allow affecting large surfaces of the head $[2,4]$. The method is applied 
in courses, it is effective, easy to use, it can be carried out even at home. The degree of laser energy penetration into the head could depend on the area of the skull that is exposed, since the skin and bones absorb light energy differently. At a wavelength of $830 \mathrm{~nm}$, depending on the specific area of the head, the penetration of light energy ranges from $0.9 \%$ to $11.7 \%$ [2-5].

The Intranasal PBMT method is aimed at bringing laser energy closer to the brain tissue. This method is often combined with transcranial PBMT. The easiest method which can be used at home is Intranasal PBMT from the Nostrils. It means bringing an additional source of laser energy through the nostrils. More complex methods that require surgical intervention include Intranasal PBMT from the Nasal Cavity and from the Nasal Submucosal Space and Intranasal PBMT from the Sphenoid Sinus [3,5]. Transcatheter endocerebral PBMT is a more complex method, which is carried out in hospital. The method means endovascularly conducting laser energy with the help of thin flexible fiber-optic instruments in the distal sections of the cerebral vascular bed directly to ischemic cerebral tissues in the area of stroke development [6,7].

To determine the localization of the cerebral atherosclerotic lesion that caused the stroke, the patient undergoes cerebral multi-gated angiography (MUGA) in the catheterization laboratory, according to the results of which the affected vascular branches are singled out. Laser exposure is performed in a catheterization laboratory. Under local anesthesia, the common femoral artery is catheterized with an introducer. Guiding catheters are conducted through this introducer under fluoroscopic control and are sent to the intracerebral branches. Through these catheters, a flexible fiber optic fiber guide instrument with a diameter of 25 to 100 micrometers is coaxially held.

A fiber optic instrument is conducted to the area of the developed stroke, where the laser action is performed. Typically, PBMT is carried out using a continuous helium-neon laser with a wavelength of $633 \mathrm{~nm}[6,7]$. After transcatheter intervention, repeated cerebral MUGA is performed, according to the results of which, the severity of intracerebral angiogenesis, collateral and capillary revascularization is judged. The method avoids the loss of laser energy when passing through various media and tissues of the skull, since light exposure is directly on the affected cerebral sections. Transcatheter intervention is performed once and does not require repeated sessions. Unlike the laser with low output power, the laser with high output power can damage biologic tissues, both at the site of exposure and in deeper layers. In this regard, the methods of their application have their own specifics, based on the selective, local destruction of some biological tissue that has a high degree of absorption of laser energy of a certain wavelength [7]. Percutaneous Transluminal Laser Angioplasty (PTLA) is aimed at destroying atherosclerotic tissues that occlude arterial vessels using laser with high output power and at restoring the main blood supply to the ischemic region $[7,8]$. The specificity of this method is that during the destruction of atherosclerotic tissues, the vascular wall and surrounding tissues should not be damaged [7]. Usually, solid state YAP: Nd laser (yttrium aluminum perovskite with conversion to the second harmonic on a nonlinear lithium iodate $\left(\mathrm{LiYO}_{3}\right)$, operating in the pulsed mode in the green region of the spectrum (wavelength $539 \mathrm{~nm}$ ) is used for PTLA of extra and intracerebral vessels.

Using this type of laser is due to the high degree of absorption of laser energy at a wavelength of $539 \mathrm{~nm}$ by atherosclerotic tissues. At the same time, the intimal and muscle layer of the vascular wall absorbs laser energy of this type in a much lesser extent, which does not lead to their destruction. When using the non-contact method, selective destruction of atherosclerotic tissues occurs. The energy in the pulse of $6-9 \mathrm{~mJ}$ with a pulse repetition rate of $3-6 \mathrm{kHz}$ does not produce a rough effect, as a result of which the products of destruction of atherosclerotic tissues are 2-4 micrometers in size, which does not lead to embolism of distal arterial bed $[7,8]$.

PTLA is carried out in a hospital setting. Similarly, as with transcatheter endocerebral PBMT, to determine the localization of the atherosclerotic lesion that caused an ischemic stroke, a diagnostic multi-gated angiography (MUGA) is performed in the catheterization laboratory to determine the localization of arterial occlusion. PTLA is performed in a catheterization laboratory under fluoroscopic and angiographic monitoring. Using guiding catheters, a flexible fiber-optic fiber guide instrument with a diameter of 100 to 200 micrometers is coaxially held. A fiber-optic instrument is conducted to the site of arterial occlusion, where laser destruction of atherosclerotic tissue is performed. After the PTLA, repeated cerebral MUGA is performed, the results of which determine the degree of restoration of arterial blood flow [8].

In conclusion, it can be justifiably said that PBMT and PTLA are highly effective, physiologically sound methods for the treatment of ischemic stroke, and they are highly important in modern neurology and laser medicine. These methods easily tolerated by patients of advanced age, they can significantly reduce the mortality and disability of gerontological patients who have had an ischemic stroke, accelerate rehabilitation and lead them to normal everyday life.

\section{References}

1. Gjulev NM, Pustozertsev VG, Gjulev SN (2002) Cerebrovascular diseases. Moscow: BINOM.

2. Hamblin MR, De Sousa MVP, Agrawal T (2016) Handbook of low-level laser therapy. Pan Stanford, New York, USA.

3. Saltmarche AE, Naeser MA, Hamblin MR, Hamblin MR, Lim L (2017) Significant improvement in cognition in mild to moderately severe dementia cases treated with transcranial plus intranasal photo biomodulation: Case series report. Photomed Laser Surg 35(8): 432441.

4. Hamblin MR (2018) Photo biomodulation for traumatic brain injury and stroke. J Neurosci Res 96(4): 731-743.

5. Salehpour F, Hamblin MR, DiDuro JO (2019) Rapid reversal of cognitive decline, olfactory dysfunction, and quality of life using multi-modality photo biomodulation therapy: case report. Photobombed Photo med Laser Surg 37(3): 159-167.

6. Maksimovich IV (2019) Transcatheter intracerebral photo biomodulation in ischemic brain disorders: clinical studies (Part 2). Photo biomodulation in the Brain. Academic Press is an imprint of Elsevier, New York, USA, pp. 529-544. 
7. Maksimovich IV (2004) Transluminal laser angioplasty in the treatment of ischemic brain lessons. Doctor of Medical Science Dissertation, Peoples' Friendship University of Russia, Mosco, Russia.
8. Maksimovich IV (2008) Method of transluminal laser revascularization of cerebral blood vessels having atherosclerotic lesions. Patent US 7490612 .

\section{For possible submissions Click below:}

